\title{
BMJ Open Rates of opioid agonist treatment prescribing in provincial prisons in Ontario, Canada, 2015-2018: a repeated cross-sectional analysis
}

\author{
Claire Bodkin (D , ${ }^{1}$ Susan Bondy, ${ }^{2}$ Leonora Regenstreif, ${ }^{1}$ Lori Kiefer, ${ }^{2,3}$ \\ Fiona Kouyoumdjian ${ }^{1}$
}

To cite: Bodkin C, Bondy S, Regenstreif L, et al. Rates of opioid agonist treatment prescribing in provincial prisons in Ontario, Canada, 2015-2018: a repeated crosssectional analysis. BMJ Open 2021;11:e048944. doi:10.1136/ bmjopen-2021-048944

- Prepublication history for this paper is available online. To view these files, please visit the journal online (http://dx.doi. org/10.1136/bmjopen-2021048944).

Received 11 January 2021 Accepted 26 October 2021

Check for updates

(C) Author(s) (or their employer(s)) 2021. Re-use permitted under CC BY-NC. No commercial re-use. See rights and permissions. Published by BMJ.

${ }^{1}$ Department of Family Medicine, McMaster University, Hamilton, Ontario, Canada

${ }^{2}$ Dalla Lana School of Public Health, University of Toronto, Toronto, Ontario, Canada ${ }^{3}$ Ontario Ministry of Community Safety and Correctional Services, Toronto, Ontario, Canada

Correspondence to Dr Claire Bodkin; claire.bodkin@medportal.ca

\section{ABSTRACT}

Objective To describe opioid agonist treatment prescribing rates in provincial prisons and compare with community prescribing rates.

Design We used quarterly, cross-sectional data on the number and proportion of people prescribed opioid agonist treatment in prison populations. Trends were compared with Ontario surveillance data from prescribers, reported on a monthly basis.

Setting Provincial prisons and general population in Ontario, Canada between 2015 and 2018.

Participants Adults incarcerated in provincial prisons and people ages 15 years and older in Ontario.

Main outcomes and measures Opioid agonist treatment prescribing prevalence, defined as treatment with methadone or buprenorphine/naloxone.

Results In prison, $6.9 \%-8.4 \%$ of people were prescribed methadone; $0.8 \%$ to $4.8 \%$ buprenorphine/naloxone; and $8.2 \%$ to $13.2 \%$ either treatment over the study period. Between 2015 and 2018, methadone prescribing prevalence did not substantially change in prisons or in the general population. The prevalence rate of buprenorphine/ naloxone prescribing increased in prisons by 1.70 times per year $(95 \% \mathrm{Cl} 1.47$ to 1.96$)$, which was significantly higher than the increase in community prescribing: 1.20 (95\% Cl 1.19 to 1.21). Buprenorphine/naloxone prescribing prevalence was significantly different across prisons. Conclusions The increase in opioid agonist treatment prescribing between 2015 and 2018 in provincial prisons shows that efforts to scale up access to treatment in the context of the opioid overdose crisis have included people who experience incarceration in Ontario. Further work is needed to understand unmet need for treatment and treatment impacts.

\section{BACKGROUND}

There is a substantial burden of opioidrelated morbidity and mortality in people who experience incarceration in Canada. ${ }^{1-4}$ Research consistently identifies high rates of substance use disorders in this population, ${ }^{5-10}$ and a majority of people report recent drug use at the time of admission to custody, ${ }^{7} 8^{11-14}$ including use of opioids, ${ }^{12}$
Strengths and limitations of this study

- This is the first study describing the rates of opioid agonist treatment prescribing in a prison population over time and during the opioid overdose crisis.

- We used whole population prescribing rates for people in prisons and in the community.

- We lack data on the prevalence of opioid use disorder to determine opioid agonist treatment coverage for people with opioid use disorder.

and a substantial proportion use drugs in custody. ${ }^{813}{ }^{15-17}$ Reliable estimates of opioid use disorder (OUD) prevalence among incarcerated and non-incarcerated people in Ontario are not available. This represents an important information gap and barrier to planning, delivery and evaluation of efforts address opioid-related harms in this setting. One Ontario study of adult men incarcerated in a provincial prison in 2009 found that $10.4 \%$ reported injection non-heroin opioid use in the year prior to incarceration, while $4.4 \%$ reported injection heroin use during the same time period. ${ }^{12}$ This is an order of magnitude higher than Jacka et al's estimate that $0.63 \%$ of the entire Ontario population used any drug intravenously in $2011 .{ }^{18}$ People who experience incarceration commonly engage in behaviours such as injecting drugs, ${ }^{5} 11121416$ 19-24 sharing needles and other paraphernalia $^{5} 1921$ 24-26 and polysubstance use, ${ }^{71}$ which increase the risk of harms such as overdose and bloodborne infections. Furthermore, evidence from Ontario reveals that the risk of death from overdose is high in this population compared with the general population, in particular, at the time of release. ${ }^{12}$ Not only do people in prison have higher rates of illicit substance use but also people who use drugs have higher rates 
of incarceration in the context of the criminalisation of drug use. ${ }^{27}$

Opioid agonist treatment (OAT) is the first-line treatment for OUD and the standard of care across Canada. ${ }^{28}$ OAT provides a long-acting opioid medication that binds to opioid receptors and prevents drug cravings and opioid withdrawal symptoms. OAT reduces both allcause and overdose mortality. ${ }^{29}$ In incarcerated populations, OAT reduces HIV transmission and complications, hepatitis $\mathrm{C}$ transmission and complications and mortality after release and improves a host of other health, social and psychological outcomes. ${ }^{30-33}$ Implementation of a state-wide correctional OAT programme in Rhode Island produced a $60.5 \%$ reduction in overdose mortality rates within 1 year of release from prison. ${ }^{34}$ OAT may also positively impact recidivism, but available evidence is limited in quantity and quality. ${ }^{35}$

Though challenges to access remain, OAT is widely available in the community and is being rapidly scaled in response to the current opioid overdose crisis. Canadian and international law confers an obligation to provide equivalent care in prison. The UN's Standard Minimum Rules for the Treatment of Prisoners, also known as the Nelson Mandela Rules, were adopted by the UN General Assembly in 2015 and call for prison healthcare services that are comparable to community services and continuity of care from the community to prison and back again. ${ }^{36}$ Despite the burden of opioid-related morbidity and mortality, evidence of OAT effectiveness and the principle of equivalence, access to OAT in correctional facilities is often limited. A recent qualitative study of OAT prescribing in provincial correctional facilities in Ontario demonstrated that many physicians working in this setting do not prescribe OAT, and a minority initiate OAT for patients in custody. ${ }^{37}$ Quantitative data from Vancouver, British Columbia revealed that among 597 recently incarcerated people with OUD, only $35 \%$ were prescribed OAT while in custody, and less that $10 \%$ of those prescribed OAT in custody were new initations. ${ }^{38}$

Information on OAT use in people in prison is important to understand whether this population has access to this evidence-based treatment, which could mitigate the risk of harms for people who experience incarceration. We aimed to describe rates of OAT prescribing in provincial prisons in Ontario, Canada between 2015 and 2018 and compared these rates with rates of OAT prescribing in the community.

\section{METHODS \\ Context}

Provincial prisons in Canada hold adults aged 18 years and older who are awaiting trial or sentencing or who are sentenced to less than 2 years in prison. In Ontario, provincial prisons are publicly funded and administered by the Ministry of the Solicitor General. We use the term 'provincial prison' to represent all provincial correctional facilities, and 'people who experience incarceration' to represent the population of those who experience detention and incarceration in provincial prisons and 'in custody' to refer to the time while in a provincial prison.

For Ontario residents, hospitalisations and medically necessary physician services are paid for through the public health insurance system, the Ontario Health Insurance Plan (OHIP), including while in provincial prison. In custody, prescribed medications are paid for by the Ministry of the Solicitor General. In the community, a subset of OHIP-eligible people are eligible for coverage of prescribed medication costs through the Ontario Drug Benefit programme, including people aged 65 years or older and people who receive benefits based on financial need and employment status or disability.

Regarding healthcare in Ontario provincial prisons, people are routinely assessed by a nurse on admission, which includes a history of prescribed medications and substance use. They are then seen by a physician or nurse practitioner in the ensuing weeks or sooner if medically indicated. The physician or nurse practitioner may order prescribed medications without seeing a patient, for example, at the time of admission for continuity of medication, or after assessing the patient. The model of care in Ontario prisons requires that every facility has at least one OAT prescriber but does not require all primary care physicians to prescribe OAT, which may represent a barrier to accessing OAT. As this study was a review of administrative health data, patients and the public were not consulted in the development of this study.

\section{Data sources}

The Ministry of the Solicitor General provided quarterly snapshot data between 2015 and 2018 on the number and proportion of people in each provincial prison who were prescribed buprenorphine/naloxone and methadone, which were the two forms of OAT available during the period under study. These snapshots were aggregate cross-sectional data of people prescribed these treatments on a single day. These data are routinely reported by healthcare staff in each provincial prison to the Ministry of the Solicitor General. The Ministry of the Solicitor General also provided data on the number of people in each prison. Data were not available by age group or gender. One prison closed in 2018 but data for that prison were included up to that date (ie, excluding the last two time periods).

We accessed data on OAT use rates and proportions in the community between 2015 and 2018 using publicly available data from the Narcotics Monitoring System (NMS), which included people ages 15 and older who received methadone or buprenorphine/naloxone in Ontario between 1 January 2015 and 31 December 2018. The NMS is administered by Ontario's Ministry of Health and collects information from dispensers on all prescribed monitored drugs dispensed to people in the community in Ontario (ie, not including people in hospital or in provincial prisons), including buprenorphine/naloxone and methadone. We accessed these data through the Ontario Prescription Opioid Tool, which is a publicly available tool that presents data on the number 
and rates of people prescribed all opioids, including OAT, in Ontario. ${ }^{39}$ These data are available as counts (absolute number of prescriptions) and a rate per 1000 population on a monthly and yearly basis. Yearly data are available by sex and by age groups. Age groups are $0-14,15-24$, 25-44, 45-64 and 65+years of age. Data for OAT were presented for ages 15 and older and so our analyses use data for age 15 and older.

\section{Statistical analysis}

We describe the rates of prescribed OAT as the per cent of people in the applicable study population prescribed OAT in the time period of data capture (prevalence rates expressed as per cent or per population size). We also estimated the rate of change in OAT prescribing prevalence between February 2015 and September 2018 across provincial prisons and the rate of change in prescribing in the community over the same time period. Rates of change were expressed as prevalence rate ratios (PRR) per year and were estimated using Poisson regression with robust SEs. Prevalence rates of opioid agonist prescribing for all of Ontario were graphed by time. We performed simple Wald contrasts to determine whether the PRRs for OAT prescribing, using pooled data across prisons, were significantly different ( $\alpha$ level of 0.05 ) from the overall provincial rates of change, in the 2015 to 2018 time period.

Following prior work on variations in prescribing practices across provincial prisons, we also explored variability in OAT prescribing across prisons and over time. ${ }^{37}$ We used box-plot graphs, which present the median prescribing rate, the 25th and 75th percentiles for prescribing rates and markers for prisons with prescribing rates outside this range. Hypothesis tests assessed whether the observed differences in prescribing rates across prisons were statistically significant as a main effect. These were conducted as overall significance tests for a main effect in prescribing rate across prison (global test for all prisons being different from the overall mean rate). Tests for overall differences across prisons were performed using negative binomial regression controlling for time of reporting. For tests of statistical significance, $\alpha$ was set at 0.05 . Analyses were performed using Stata software, V.16 (StataCorp).

\section{Patient and public involvement}

Three of the authors have clinical practices caring for people who are currently or formerly incarcerated. The research question emerged from their patient's experiences of trying to access OAT while incarcerated. There was no formal patient or public involvement in the project design, data collection or analysis.

\section{RESULTS}

We examined data for 26 provincial prisons. We had cross-sectional prescribing data for provincial prisons at two time points in 2015, four time points in 2016, four time points in 2017 and two time points in 2018. During the period under study, the cross-sectional population size for the included provincial prisons ranged from 11

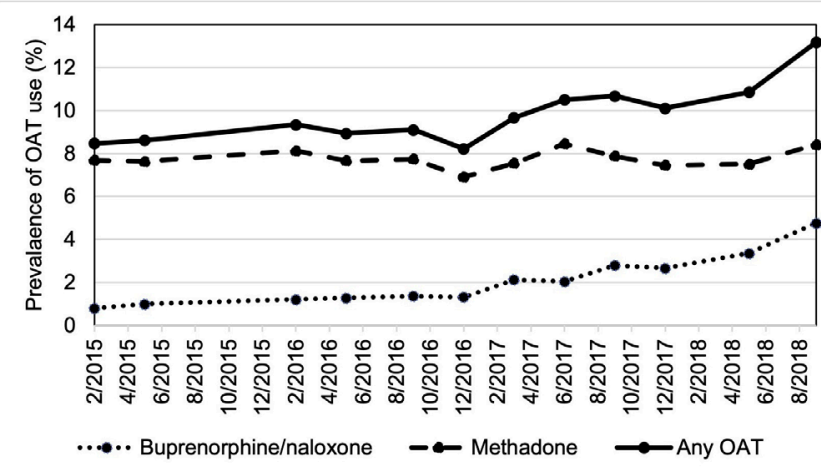

Ontario provincial prisons

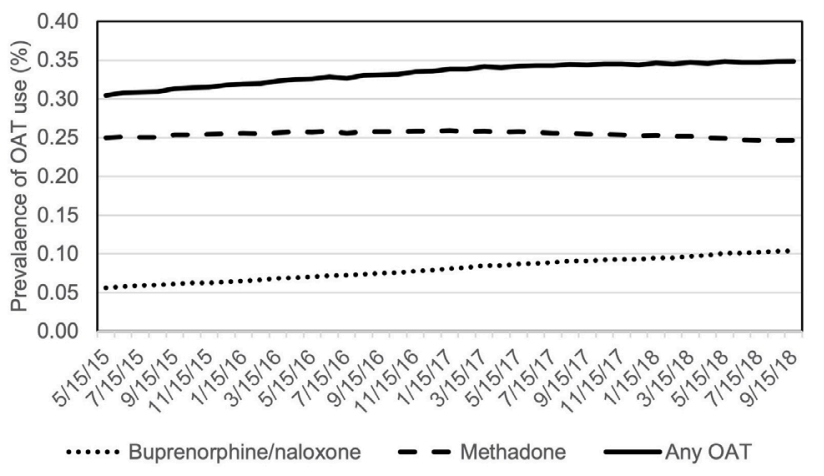

Ontario whole population

Figure 1 Percentage of people prescribed OAT in provincial prisons and in the whole population in Ontario, 2015-2018 by OAT type. OAT, opioid agonist treatment.

people in the smallest prison to 1096 , and the total population across the 26 provincial prisons ranged between 7140 and 8122.

Over the study period and across provincial prisons, the total percentage of people treated with methadone ranged between $6.9 \%$ and $8.4 \%$, with buprenorphine/ naloxone ranged between $0.8 \%$ and $4.8 \%$ and with either treatment ranged between $8.2 \%$ and $13.2 \%$ (figure 1).

As shown in table 1, methadone prescribing did not increase significantly in the prison population between 2015 and 2018 and decreased by a factor of 0.99 per year in the whole population. In contrast, buprenorphine/ naloxone prescribing increased significantly in provincial prisons as well as in the whole population: the prevalence rate increased in provincial prisons by a factor of 1.70 per year, which was significantly higher than the increase in prescribing for the whole population, where the prevalence rate increased by 1.20 times per year.

The percentage of people prescribed OAT was variable across provincial prisons, as shown in figure 2. Methadone prescribing across prisons was fairly consistent over the time period. Buprenorphine/naloxone prescribing across prisons increased over the time period with the median prevalence, and 25th and 75th percentiles all increasing over the period under study. Relative to the overall pattern for methadone, buprenorphine/ naloxone prescribing was more variable across prisons, 
Table 1 Prevalence rate ratio of trends in prescribed methadone, buprenorphine/naloxone or either in Ontario, Canada, 20152018

\begin{tabular}{|c|c|c|c|c|c|c|c|c|c|}
\hline & \multicolumn{4}{|c|}{ Provincial prison population* } & \multicolumn{4}{|c|}{ Whole population } & \multirow[b]{2}{*}{$\begin{array}{l}\text { Are PRRs } \\
\text { different? }\end{array}$} \\
\hline & PRR & $95 \% \mathrm{Cl}$ & & $\begin{array}{l}\text { P value } \\
\text { for trend }\end{array}$ & PRR & $95 \% \mathrm{Cl}$ & & $\begin{array}{l}P \text { value for } \\
\text { trend }\end{array}$ & \\
\hline $\begin{array}{l}\text { Buprenorphine/ } \\
\text { naloxone }\end{array}$ & 1.70 & 1.47 & 1.96 & 0.000 & 1.20 & 1.19 & 1.21 & 0.000 & $\mathrm{p}<0.001$ \\
\hline Any OAT & 1.12 & 1.04 & 1.21 & 0.003 & 1.04 & 1.04 & 1.04 & 0.000 & $p<0.001$ \\
\hline
\end{tabular}

*26 provincial prisons in Ontario.

OAT, opioid agonist treatment; PRR, prevalence rate ratio.

with several prisons being outliers with prescribing rates far higher than those seen in the lower $75 \%$ of all prisons.

The difference in prescribing prevalence between prisons was statistically significant, as a main effect for prison, and beyond variability by chance. Results for the global tests contrasting prevalence across all 26 prisons relative to the provincial average in prisons (testing as a main effect) were statistically significant $(p<0.001 ; 25$ df) in all cases. Results from likelihood ratio tests for prisons after controlling for date of data collection were similarly statistically significant for all three models for methadone, buprenorphine/naloxone and overall OAT $(\mathrm{p}<0.001 ; 25 \mathrm{df})$. The same modelling confirmed that there was no statistically significant trend over time in methadone prescribing, during this time window (there was no trend treating date as a continuous variable or for reporting date treated as categorical). All analyses found significant effects for both date (ie, trend over time) and across prisons (as a categorical main effect) for buprenorphine/naloxone prescribing and any OAT prescribing.

\section{DISCUSSION}

This study demonstrates that rates of OAT prescribing increased over the study period in provincial prisons. This may reflect increased need over time, as opioid-related emergency department visits and mortality in Ontario increased year-over-year from 2015 to 2018 and hospitalisations increased every year but one from 2015 to 2018 . $^{40}$ It may also reflect changes in accessibility or acceptance of OAT in Ontario prisons. We also found there were highly variable rates of OAT prescribing across provincial prisons for the same time period, which is unlikely to be solely attributable to variation in patient eligibility for and interest in treatment. Some of the differences in rates of OAT prescribing between prisons may reflect regional variability in community prescribing, which we did not assess in this study.

This study has several limitations. Information on OAT prescribing was only available as quarterly point-in-time data. These data do not differentiate between initiation of OAT and continuation of OAT in provincial prison, and this information would be relevant for developing interventions to improve OAT access and quality in prisons. In the absence of individual-level clinical data, we are unable to examine characteristics of individuals treated over time or assess whether there was continuity of OAT on admission and release. We are also not able to understand whether people have access to OAT, for example, whether people were offered OAT on admission if indicated or indicators of high-quality OAT, such as whether dose was increased in a timely fashion and whether a therapeutic dose was achieved. Further information from charts and from people in prisons would provide additional information. Information on OAT receipt and OAT coverage in the community was available in age groups that did not match the age group of the incarcerated population; community data were presented for the age group of 15 years of age and older, while the incarcerated population was ages 18 and up.

A recent study of Berlin prisons examined similar questions regarding prevalence of OAT prescribing. ${ }^{41}$ They found that $6.8 \%$ of the incarcerated population was on OAT. We found a substantially higher prevalence rate, which may be due to differing need between these two contexts. Our study adds to that by including data over a several year period, for a large population, in North America during opioid overdose crisis and compares across institutions and with community. In comparison, theirs is very recent and only examines a single point in time; however, they were able to determine the prevalence of opioid dependence and, thus, look at treatment coverage.

Describing the rates and variability in OAT prescribing in prisons provides stakeholders with a starting point to understand and address gaps in access to evidence-based first-line treatment for OUD within the provincial prison system. While it is encouraging to see an upward trend in correctional OAT prescribing in this population, the degree to which treatment needs are being met in this setting remains unclear as we lack data on the prevalence of OUD in people in Ontario provincial prisons. To support health system and treatment planning, research is needed to determine the prevalence of OUD and to describe OAT access, initiation and continuity for people who experience incarceration. Such work would be facilitated through the use of clinical data as well as 

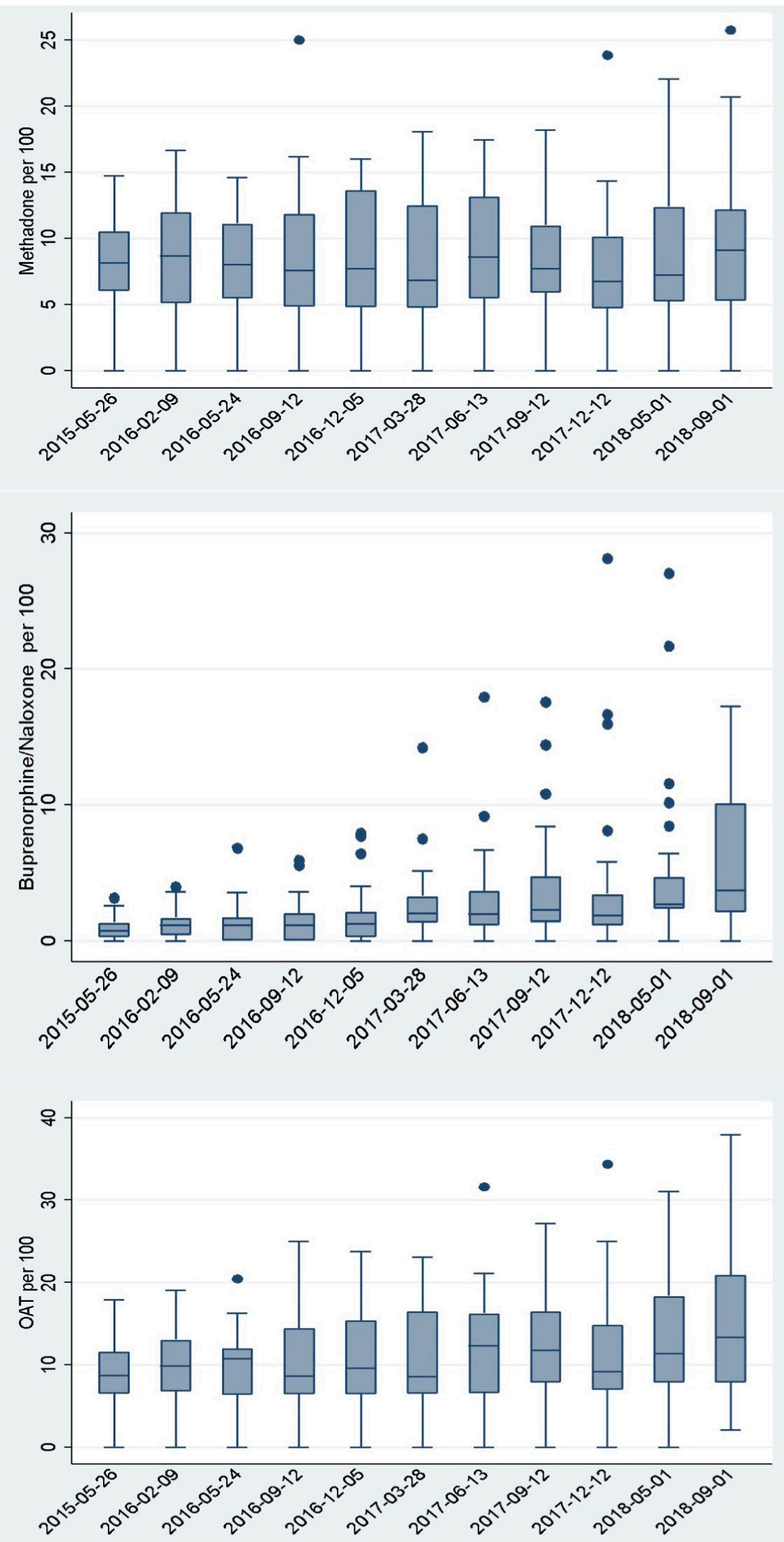

Figure 2 Box plots* of percent of people prescribed methadone, buprenorphine/naloxone or either per quarter across provincial prisons in Ontario, 2015-2018. *The centre line indicates the median prevalence of prescribing, and the box shows the range in rates for the 25th and 75th percentiles for prevalence of prescribing; dots indicate provincial prisons with extreme prevalence rates. OAT, opioid agonist treatment. 
administrative data, and the lack of an electronic medical record in Ontario provincial prisons is a current barrier to data collection and analysis. In addition, research should explore differences between prisons that may prevent or promote access to high-quality OAT and facilitators to OAT access in other jurisdictions that have successfully improved OAT access.

Research and public health interventions should also consider the structural forces that create an environment where people who use drugs are more likely to experience incarceration. Criminalisation of drug use ipso facto leads to incarceration, and structural factors such as homelessness, poverty, racism and colonisation create conditions that further increase the risk of incarceration. Lack of access to OAT in prison in turn exacerbates the health effects of structural oppression. Increasing OAT access may also reduce the likelihood of subsequent incarceration. ${ }^{42}$

This study demonstrates that OAT prescribing increased substantially between 2015 and 2018 in provincial prisons in Ontario, Canada. Furthermore, there was significant variation in prescribing prevalence between different prisons. Future research is needed on OUD prevalence in people in prisons and on institutional and system level factors that promote or inhibit access to OAT. In the meantime, health and correctional staff and administration should work to support universal access to highquality OAT for people with OUD in provincial prison and after release. Supporting treatment for OUD could prevent the substantial burden and harms associated with opioid use in this population.

\section{Twitter Claire Bodkin @healthinthehmmr}

Contributors FK conceived and supervised the investigation and contributed to study design, and is responsible for the overall content as the guarantor. SB directed the statistical analyses and contributed to study design. CB contributed to study design and wrote the first draft of the manuscript. LK and FK contributed to data acquisition. FK, SB, CB LK and LR contributed to interpretation of analyses, critically reviewed and revised the manuscript and approved the final version.

Funding Funding support was provided by the Canadian Institutes of Health Research through the Canadian Research Initiative in Substance Misuse (SMN-139150).

Competing interests $L R$ received honoraria from Indivior for giving presentations on Sublocade and for Advisory Board participation on Sublocade and Suboxone film. We have no other competing interests to disclose.

Patient and public involvement Patients and/or the public were not involved in the design, or conduct, or reporting, or dissemination plans of this research.

\section{Patient consent for publication Not applicable.}

Ethics approval This study was approved by the Hamilton Integrated Research Ethics Board (number 5878). Consistent with the Tri-Council Policy Statement: Ethical Conduct for Research Involving Humans-TCPS 2 (2018), we did not obtain individual consent for study participation; we accessed only aggregate data and it would not be feasible to identify or contact those whose data we used.

Provenance and peer review Not commissioned; externally peer reviewed.

Data availability statement Data may be obtained from a third party and are not publicly available. We are not able to share data because of restrictions specified in our Research Agreement with the Ministry of the Solicitor General. To request access to data, interested persons could contact mcscsresearch@ontario.ca.

Open access This is an open access article distributed in accordance with the Creative Commons Attribution Non Commercial (CC BY-NC 4.0) license, which permits others to distribute, remix, adapt, build upon this work non-commercially, and license their derivative works on different terms, provided the original work is properly cited, appropriate credit is given, any changes made indicated, and the use is non-commercial. See: http://creativecommons.org/licenses/by-nc/4.0/.

ORCID iD

Claire Bodkin http://orcid.org/0000-0001-9560-1818

\section{REFERENCES}

1 Groot E, Kouyoumdjian FG, Kiefer L, et al. Drug toxicity deaths after release from incarceration in Ontario, 2006-2013: review of coroner's cases. PLoS One 2016;11:e0157512.

2 Kouyoumdjian FG, Kiefer L, Wobeser W, et al. Mortality over 12 years of follow-up in people admitted to provincial custody in Ontario: a retrospective cohort study. CMAJ Open 2016;4:E153-61.

3 Green S, Foran J, Kouyoumdjian FG. Access to primary care in adults in a provincial correctional facility in Ontario. BMC Res Notes 2016;9:131

4 Kouyoumdjian F, Schuler A, Matheson FI, et al. Health status of prisoners in Canada: narrative review. Can Fam Physician 2016;62:215-22.

5 A health care needs assessment of federal inmates in Canada. Can J Public Health 2004:95:S9-63.

6 Rezansoff SN, Moniruzzaman A, Gress C, et al. Psychiatric diagnoses and multiyear criminal recidivism in a Canadian provincial offender population. Psychology, Public Policy, and Law 2013;19:443-53.

7 Mullins P, Farrell S. Offender substance use patterns-aboriginal and non-aboriginal offenders. Research Branch, Correctional Service Canada, 2012.

8 Smith A, Cox K, Poon C, et al. Time out III: a profile of BC youth in custody. Vancouver, BC: McCreary Centre Society, 2013.

9 Beaudette J. Prevalence of mental health disorders among incoming federal offenders. Atlantic, Ontario, \& Pacific Regions: Research Branch, Correctional Service Canada, 2013.

10 Kouyoumdjian FG, Cheng SY, Fung K, et al. The health care utilization of people in prison and after prison release: a population-based cohort study in Ontario, Canada. PLoS One 2018;13:e0201592.

11 Nicholls TL, Lee Z, Corrado RR, et al. Women inmates' mental health needs: evidence of the validity of the jail screening assessment tool (JSAT). Int J Forensic Ment Health 2004;3:167-84.

12 Kouyoumdjian FG, Calzavara LM, Kiefer L, et al. Drug use prior to incarceration and associated socio-behavioural factors among males in a provincial correctional facility in Ontario, Canada. Can J Public Health 2014;105:e198-202.

13 Plourde C, Brochu S, Gendron A, et al. Pathways of substance use among female and male inmates in Canadian federal settings. Prison J 2012;92:506-24.

14 Zakaria D, Borgatta F, Jarvis A, et al. Summary of emerging findings from the 2007 national inmate infection diseases and risk-behaviours survey. Correctional Service of Canada, Research Branch, 2010.

15 Kunic D, Grant BA. The computerized assessment of substance abuse (CASA): results from the demonstration project. Research Branch, Correctional Service of Canada, 2006.

16 Martin RE, Remple V, Gold F, et al. Drug use and risk of bloodborne infections. Can J Public Health 2005;96:97-101.

17 Grant BA, Varis DD, Lefebvre D. Intensive support units (ISU) for federal offenders with substance abuse problems: an impact analysis. Correctional Service Canada, 2005.

18 Jacka B, Larney S, Degenhardt L, et al. Prevalence of injecting drug use and coverage of interventions to prevent HIV and hepatitis C virus infection among people who inject drugs in Canada. $\mathrm{Am} \mathrm{J}$ Public Health 2020;110:45-50.

19 Calzavara LM, Burchell AN, Schlossberg J, et al. Prior opiate injection and incarceration history predict injection drug use among inmates. Addiction 2003:98:1257-65.

20 Johnson SL, Moser A, Cheverie M. Assessing the impact of enhanced drug interdiction activities at Kingston penitentiary: a pilot study. Correctional Service of Canada, Research Branch, 2011.

21 Robinson D, Mirabelli L. Summary of findings of the 1995 CSC national inmate survey. Correctional Service Canada, Correctional Research \& Development, 1996.

22 Network CHAL. Canada: study provides further evidence of risk of hepatitis C and HIV transmission in prisons. HIV AIDS Policy Law Rev 2004;9:2.

23 DeBeck K, Kerr T, Li K, et al. Incarceration and drug use patterns among a cohort of injection drug users. Addiction 2009;104:69-76. 
24 Farrell S, Ross J, Ternes M, et al. Prevalence of injection drug use among male offenders. Research Branch, Correctional Service Canada, 2010

25 Buxton JA, Rothon D, Durigon M, et al. Hepatitis C and HIV prevalence using oral mucosal transudate, and reported drug use and sexual behaviours of youth in custody in British Columbia. Can $J$ Public Health 2009;100:121-4.

26 Ford PM, Pearson M, Sankar-Mistry P. HIV, hepatitis C and risk behaviour in a Canadian medium-security federal penitentiary. QJM 2000;93:113-9.

27 Fischer B, Cruz MF, Rehm J. Illicit opioid use and its key characteristics: a select overview and evidence from a Canadian multisite cohort of illicit opioid users (OPICAN). Can J Psychiatry 2006;51:624-34.

28 Bruneau J, Ahamad K, Goyer Marie-Ėve, et al. Management of opioid use disorders: a national clinical practice guideline. CMAJ 2018;190:E247-57.

29 Sordo L, Barrio G, Bravo MJ, et al. Mortality risk during and after opioid substitution treatment: systematic review and meta-analysis of cohort studies. BMJ 2017;357:j1550.

30 Kamarulzaman A, Reid SE, Schwitters A, et al. Prevention of transmission of HIV, hepatitis $B$ virus, hepatitis $C$ virus, and tuberculosis in prisoners. Lancet 2016;388:1115-26.

31 Hedrich D, Alves P, Farrell M, et al. The effectiveness of opioid maintenance treatment in prison settings: a systematic review. Addiction 2012;107:501-17.

32 Marsden J, Stillwell G, Jones $\mathrm{H}$, et al. Does exposure to opioid substitution treatment in prison reduce the risk of death after release? A national prospective observational study in England. Addiction 2017;112:1408-18.
33 Degenhardt L, Larney S, Kimber J, et al. The impact of opioid substitution therapy on mortality post-release from prison: retrospective data linkage study. Addiction 2014;109:1306-17.

34 Green TC, Clarke J, Brinkley-Rubinstein L, et al. Postincarceration fatal overdoses after implementing medications for addiction treatment in a statewide correctional system. JAMA Psychiatry 2018;75:405-7.

35 Perry AE, Neilson M, Martyn-St James M. Pharmacological interventions for drug-using offenders. Cochrane Data Syst Rev 2015;6.

36 Assembly UNG. United nations standard minimum rules for the treatment of prisoners (the Nelson Mandela rules), 2015.

37 Kouyoumdjian FG, Patel A, To MJ, et al. Physician prescribing of opioid agonist treatments in provincial correctional facilities in Ontario, Canada: a survey. PLoS One 2018;13:e0192431.

38 Bozinoff N, DeBeck K, Milloy M-J, et al. Utilization of opioid agonist therapy among incarcerated persons with opioid use disorder in Vancouver, Canada. Drug Alcohol Depend 2018;193:42-7.

39 Ontario Prescription Opioid Tool. Ontario drug policy research network, 2020. Available: https://odprn.ca/ontario-opioid-drugobservatory/ontario-prescription-opioid-tool/ [Accessed 1 Sep 2020].

40 Interactive Opioid Tool. Queen's printer for Ontario, 2020. Available: https://www.publichealthontario.ca/en/data-and-analysis/substanceuse/interactive-opioid-tool

41 von Bernuth K, Seidel P, Krebs J, et al. Prevalence of opioid dependence and opioid agonist treatment in the Berlin Custodial setting: a cross-sectional study. Front Psychiatry 2020;11:794.

42 Russolillo A, Moniruzzaman A, McCandless LC, et al. Associations between methadone maintenance treatment and crime: a 17-year longitudinal cohort study of Canadian provincial offenders. Addiction 2018;113:656-67. 